\title{
Peri-articular Methylprednisolone Acetate Injection for the Treatment of Primary Osteoarthritis of the Distal Interphalangeal Joints
}

\author{
Fadi Khazin ${ }^{1}$ and George Habib ${ }^{2 *}$ \\ ${ }^{1}$ Department of Orthopedics, Lady Davis Medical center, Israel \\ ${ }^{2}$ Rheumatology Unit, Laniado medical center, Netanya and Rheumatology clinic, Nazareth Hospital, Nazareth, Azrieli Faculty of Medicine, Bar-Ilan \\ University, Safed, Israel
}

Submission: June 28, 2021; Published: July 07, 2021

*Corresponding author: George Habib, M.D., M.P.H Rheumatology Unit, Laniado medical center, Netanya 4244916, Israel

\begin{abstract}
Background: Treatment options of painful degenerative changes of the distal interphalangeal joints (DIPJ) could be futile. Local subcutaneous peri-articular injection of steroids mixed with lidocaine, was evaluated.

Material and Methods: Consecutive patients with symptomatic osteoarthritis of the DIPJ for more than 4-weeks without favorable response to non-steroidal anti-inflammatory medications, were asked to participate in our study. All patients had demographic, clinical and lab parameters including hand x-rays, documented. These patients had subcutaneous peri-articular injection the superior lateral and medial sides of each painful DIPJ of one hand of $4 \mathrm{mg}(0.1 \mathrm{ml})$ of methylprednisolone acetate (MPA) mixed with $0.05 \mathrm{ml}$ of $1 \%$ lidocaine at each side (group 1). DIPJ area pain level prior to and one, four and ten weeks following the local injections were evaluated using visual analogue scale (VAS). Age and sex-matched group of patients (group 2, control group), received $0.1 \mathrm{ml}$ of normal saline mixed with $0.05 \mathrm{ml}$ of $1 \%$ lidocaine, using the same approach.
\end{abstract}

Results: Fourteen and 11 patients were recruited in groups 1 and group 2, respectively during 13-month period. There were 11 females and 3 male patients in group 1, with mean age of $48.5 \pm 8.9$ years. Mean VAS values at baseline were 73 and 62 in groups 1 and 2, respectively, and 36 $(\mathrm{p}=0.0001), 48(\mathrm{p}=0.004)$ at week $1,55(\mathrm{p}=0.001), 57(\mathrm{p}=0.286)$ at week $4,59(\mathrm{p}=0.021), 59(\mathrm{p}=0.285)$, at week 10, respectively.

Conclusion: Subcutaneous peri-articular injection of MPA mixed with lidocaine significantly reduced DIPJ osteoarthritis pain, for at least 10 weeks.

Keywords: Peri-articular; Subcutaneous; Methylprednisolone injection; Distal interphalangeal joint; Primary osteoarthritis of hands

Abbreviation: POAH: Primary Osteoarthritis of the Hands; DIPJ: Distal Interphalangeal Joint; MPA: Methylprednisolone Acetate; VAS: Visual Analogue Scale

\section{Introduction}

Primary osteoarthritis of the hands (POAH) is not rarely encountered in clinical practice, affecting women more than men with a strong genetic predisposition [1,2]. Its prevalence increases with age [3] and it reflects degenerative changes consisting of joint space narrowing, new bone formation and subchondral cysts $[4,5]$. Patients usually seek rheumatology opinion for either local pain, stiffness and/or deformity of the proximal and/or distal interphalangeal joint/s (DIPJ)/s. The mechanism of DIPJ pain in $\mathrm{POAH}$, is poorly understood. In general, chronic pain in areas of joint osteoarthritis is believed to be from different sources, including damaged cartilage, local synovitis, local bone marrow abnormalities and/or neuronal sources [6].
Pain at the DIPJ could be acute or chronic and treatment includes non-steroidal anti-inflammatory tablets or ointments, simple analgesics, paraffin baths, local intra-articular corticosteroid injections or even alternative treatments $[7,8]$. The utility of these treatments could be limited, and an attempting a local intra-articular injection at the tiny DIPJ, is usually not an easy task, and could be associated with a lot of pain. In a previous controlled study, we showed that peri-articular subcutaneous injection at the lateral and medial parts of the painful proximal interphalangeal joint of patients with $\mathrm{POAH}$, had resulted in a significant pain reduction, lasting at least for 10 weeks [9]. There are no studies in the literature about the efficacy of intra- or peri- 
articular steroid injection at the DIPJ area, on pain level among patients with POAH of the DIPJs. In this case control study, we evaluated the clinical effect of local peri-articular subcutaneous injection of methylprednisolone acetate (MPA) mixed with lidocaine at both lateral and medial sides of the DIPJ, in terms of pain relief.

\section{Materials and Methods}

Patients consecutively seen at the outpatient rheumatology clinic in our hospital, with painful POAH of the DIPJ, were recruited. Chingford Study was considered as a reference for the diagnosis of POAH of the DIPJs [10]. After consent, demographic, clinical and laboratory parameters of the patients were documented. Visual analogue scale (VAS) was used to grade DIPJ level of pain with a scale between 100 (worse pain experienced ever) to 0 (no pain). Patients had peri-articular sterile injection of the painful DIPJs of a single hand (the one with more pain, or the one preferred by the patient). The injections were performed utilizing $1 \mathrm{ml}$ syringe with a built-in $8 \mathrm{~mm}$ long 29/30 G needle, inserted subcutaneously at the superior lateral and medial parts of the DIPJ line, at an angle of about $40^{\circ}$ after producing some skin fold by the examiner's other hand (injector) (Figure 1). A $4 \mathrm{mg}(0.1 \mathrm{ml})$ of methylprednisolone acetate (MPA) (Pfizer, Rijksweg, Belgium), mixed with $0.05 \mathrm{ml}$ of lidocaine 1\% (Teva, Petach Tekva, Israel), were injected at each side (group 1). Repeated evaluations for joint pain were performed 1, 4 and 10 weeks following the local injection, at the same clinic. An age- and sex-matched patients (group 2, control group) from the same hospital, with painful POAH of the DIPJ, were recruited and injected with $0.1 \mathrm{ml}$ of normal saline mixed with $0.50 \mathrm{ml}$ lidocaine $1 \%$ (Teva, Petach Tekva, Israel), using the same approach.

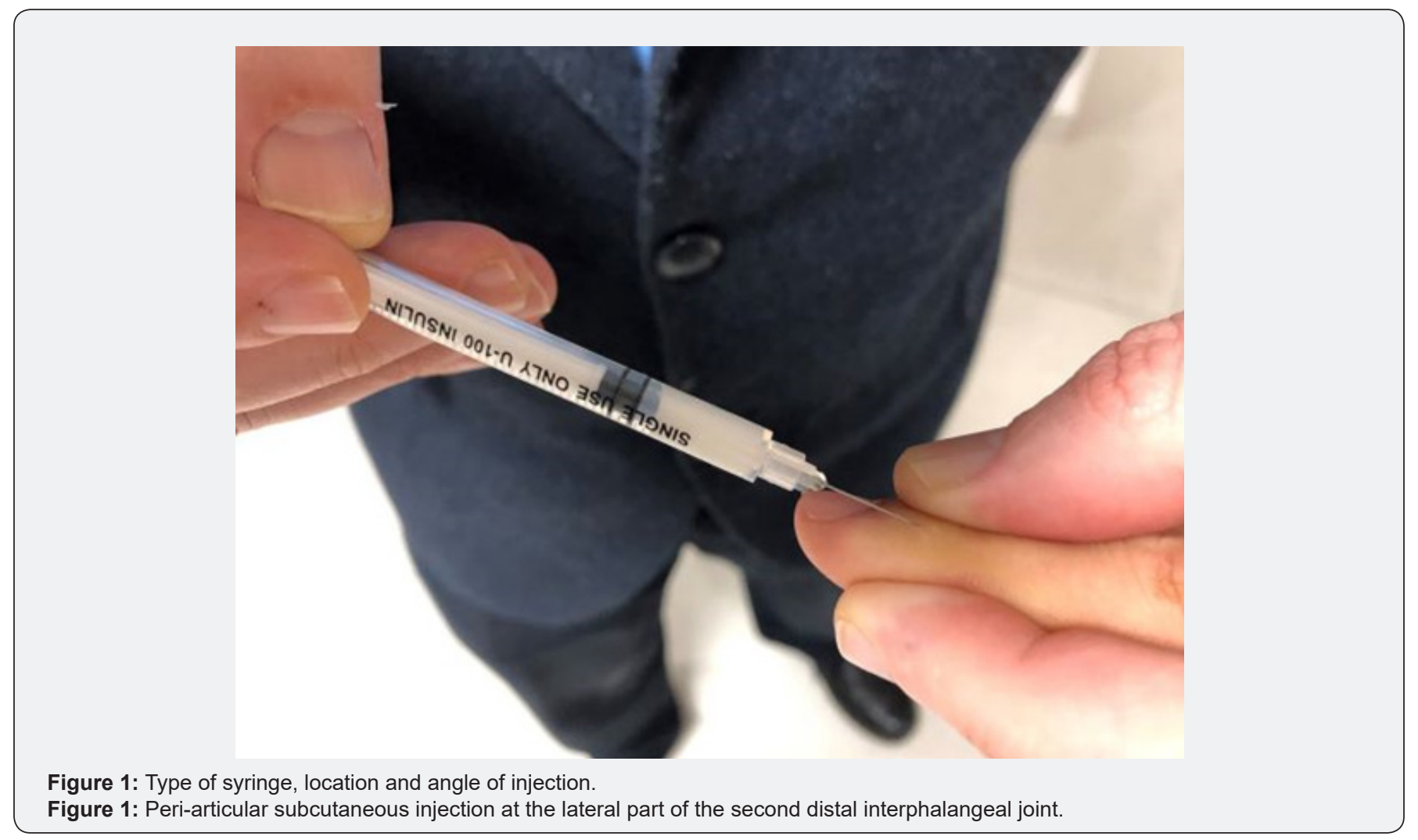

Exclusion criteria included patients with cellulitis at the DIP area, patients with DIPJ pain of less than 4 weeks, patients who were previously injected at or around the DIP Joint during the last 3 months, patients with evidence of psoriasis, patients unable to sign a consent form and/or unable to come for follow up.

Wilcoxon's ranks signed test, was used to compare between patients' VAS scores at each time point with the VAS scores at baseline, and between the parameters of the two groups at baseline, using SPSS software (SPSS Inc., Chicago, USA), version 22. This study was approved by the local ethics committee of the hospital.

\section{Results}

Fourteen and 11 patients were recruited in groups 1 and 2 respectively, during 13-month period. Data in Table 1 summarizes different clinical and demographic parameters of the participants from group 1 and group 2. The was no significant difference in any parameter. Data in Tables 2 \& 3, summarize the VAS values at different time points of all the participants from group 1 and group 2 respectively. 


\section{Orthopedics and Rheumatology Open Access Journal (OROAJ)}

Table 1: Demographic, clinical and radiographic parameters of the patients at baseline.

\begin{tabular}{|c|c|c|}
\hline Parameter & Group 1 & Gesults \\
\hline & $11: 3$ & $8: 3$ \\
\hline F:M & 0.756 & $51 \pm 7.6,46-69$ \\
\hline - Age* & $48.5 \pm 8.9,44-71$ & $8.456 \quad 2 \pm 2.1,5-10$ \\
\hline - Duration of pain* (wks) & $7.7 \pm 2.3,4-11$ & $1.3 \pm 0.48,1-2$ \\
\hline - No. of DIPJ injected* & $1.4 \pm 0.51,1-2$ & 0.644 \\
\hline - VAS* & $73 \pm 10.12,59-96$ & $62 \pm 10.7,49-81$ \\
\hline - C-RP* & $2.48 \pm 2.45,0.1-7.2$ & 0.134 \\
\hline
\end{tabular}

${ }^{*}$ Mean $\pm \mathrm{SD}$, range

$\mathrm{F}=$ female, $\mathrm{M}=$ male, $\mathrm{DIPJ}=$ proximal interphalangeal joint, $\mathrm{VAS}=$ visual analogue scale, $\mathrm{C}-\mathrm{RP}=\mathrm{C}$-reactive protein, wks=weeks

Table 2: VAS score at different time points among group 1 patients.

\begin{tabular}{|c|c|c|c|c|}
\hline \multirow{2}{*}{ Patient } & \multirow{2}{*}{ VAS at base line } & VAS at & VAS at & VAS at \\
\hline & & W1 & W4 & W10 \\
\hline 1 & 78 & 25 & 33 & 55 \\
\hline 2 & 67 & 35 & 44 & 62 \\
\hline 3 & 72 & NA & 75 & 80 \\
\hline 4 & 89 & 90 & 87 & 86 \\
\hline 5 & 64 & 32 & 44 & 34 \\
\hline 6 & 59 & 34 & 23 & 60 \\
\hline 7 & 67 & 50 & 46 & 36 \\
\hline 8 & 64 & 46 & 72 & 68 \\
\hline 9 & 76 & 14 & NA & 44 \\
\hline 10 & 68 & 10 & 15 & 70 \\
\hline 11 & 76 & 44 & 35 & 41 \\
\hline 12 & 66 & 55 & 60 & 70 \\
\hline 13 & 96 & 42 & 24 & NA \\
\hline 14 & 74 & 32 & 12 & 60 \\
\hline Mean & 73 & 36 & 55 & 59 \\
\hline$P$ value & & 0.000 & 0.001 & 0.021 \\
\hline
\end{tabular}

VAS: Visual analogue scale; W1: 1 week following the peri-articular injection; W4: 4 weeks following the peri-articular injection, W10: 10 weeks following the peri-articular injection, NA: Not available 
Table 3: VAS score at different time points among group 2 patients.

\begin{tabular}{|c|c|c|c|c|}
\hline \multirow{2}{*}{ Patient } & \multirow{2}{*}{ VAS at baseline } & VAS at & VAS at & VAS at \\
\cline { 2 - 5 } & & W1 & W4 & W10 \\
\hline 1 & 65 & 61 & 78 & 44 \\
\hline 2 & 72 & 58 & 62 & 53 \\
\hline 3 & 49 & 41 & 53 & 72 \\
\hline 4 & 81 & 72 & 48 & 74 \\
\hline 5 & 68 & 42 & 72 & 34 \\
\hline 6 & 62 & 38 & 49 & 33 \\
\hline 7 & 59 & 46 & 64 & 52 \\
\hline 8 & 72 & 32 & 28 & 63 \\
\hline 10 & 48 & 38 & 62 & 61 \\
\hline Mean & 51 & 53 & 57 & 51 \\
\hline P value & 56 & 49 & 0.286 & \\
\hline
\end{tabular}

VAS: Visual analogue scale; $W 1=1$ week following the peri-articular injection, W4: 4 weeks following the peri-articular injection, W10: 10 weeks following the peri-articular injection, NA: Not available

\section{Discussion}

Subcutaneous peri-articular injection of steroids, at the DIPJ had resulted in a significant reduction in joint area pain, lasting for at least 10 weeks. Although VAS values at the control group improved also at different time points, however, this improvement was significant at week 1 only. This transient significant improvement at week 1 in the control group, could be partly the result of the transient effect of lidocaine. Though there is no data about the effect of local lidocaine injection on joint pain. As mentioned in the introduction, the mechanism of DIPJ pain in POAH, is poorly understood. In general, chronic pain in areas of joint osteoarthritis is believed to be from different sources, including damaged cartilage, local synovitis, local bone marrow abnormalities and/or neuronal sources [6]. The role of other findings such as new bone formation, overlying skin and joint capsule, is not clear. These last structures seem to also have an important role in the mechanism of DIPJ pain, since usually mainly those patients with bony prominences (Heberden's nodes) complain of pain and have prominent local tenderness. We believe that the injected steroids with lidocaine, infiltrate mainly in the subcutaneous areas, possibly also around, within and into the joint capsule reaching ligaments, tendons, fat tissue, synovial tissue, cartilage and bone. Glucocorticoids reduce pain by inhibiting prostaglandin synthesis, which leads to inflammation, and reducing vascular permeability that results in tissue edema. Corticosteroids have been shown also to reduce spontaneous discharge in an injured nerve, which reduces neuropathic pain [11].
More studies are really needed to better clarify the source of pain among patients with primary DIPJ osteoarthritis. Technically, using a small diameter built-in needle has a huge advantage in first; being able to penetrate to the subcutaneous are with relatively minimal pain, and secondly; in avoiding the possibility of splashing around the mixed steroids on the cloths of both patient and examiner causing an unpleasant feeling. This unwarranted effect results from the local pressure created by the injected material in a tiny subcutaneous area. If a skin fold cannot be produced at the joint line, more proximal approach (1-3 mm) can be attempted. Following the procedure, patients can behave normally in terms of hand function. This study has some limitation, mainly the small number of the participants. However, the existence of the control group and the comparison of the VAS values at different time points to baseline values, gives more power to the results. Primary DIPJ osteoarthritis could be very painful and resistant to the limited modalities of treatment, local steroid + lidocaine injection could be very relieving with no significant adverse effects.

\section{Conclusion}

Subcutaneous peri-articular injection of MPA mixed with lidocaine significantly reduced DIPJ pain, among patients with resistant painful primary osteoarthritis of the hands, for at least 10 weeks.

\section{Acknowledgement}

None. 


\section{Conflict of Interest}

None.

\section{References}

1. Sun X, Zhen X, Hu X, Li Y, Gu S, et al (2019). Osteoarthritis in the MiddleAged and Elderly in China: Prevalence and Influencing Factors. Int J Environ Res Public Health 16(23): 4701.

2. Ishimori ML, Altman RD, Cohen MJ, Cui J, Guo X, et al. (2010) Heritability patterns in hand osteoarthritis: the role of osteophytes. Arthritis Res Ther 12(5): R180.

3. Haugen IK, Englund M, Piran Aliabadi, Jingbo Niu, Margaret Clancy, et al. (2011) Prevalence, incidence and progression of hand osteoarthritis in the general population: the Framingham Osteoarthritis Study. Ann Rheum Dis 70(9): 1581-1586.

4. Zhang Y, Niu J, Kelly-Hayes M, Chaisson CE, Aliabadi P, et al. (2002) Prevalence of symptomatic hand osteoarthritis and its impact on functional status among the elderly: the Framingham Study. Am J Epidemiol 156(1): 1021-1027.

5. Toba N, Sakai A, Aoyagi K, Yoshida S, Honda S, et al. (2006) Prevalence and involvement patterns of radiographic hand osteoarthritis in Japanese women: the Hizen-Oshima Study. J Bone Mineral Metab 24(4): 344-348
6. Eitner A, Hofmann GO, Schaible HG (2017) Mechanisms of Osteoarthritic Pain. Studies in Humans and Experimental Models. Front Mol Neurosci 10: 349.

7. Zhang W, Doherty M, Leeb BF, Alekseeva L, Arden NK, et al. (2007) EULAR evidence-based recommendations for the management of hand osteoarthritis: report of a Task Force of the EULAR Standing Committee for International Clinical Studies Including Therapeutics (ESCISIT) Ann Rheum Dis 66(3): 377-388.

8. Sayyid R, Uthman I (2015) Hand osteoarthritis, an update on therapy. Archives of rheumatology 30(2): 150-158.

9. Habib G, Sakas F, Artul S, Khazin F (2018) The Effect of periarticular injection of methylprednisolone acetate in patients with primary osteoarthritis of the proximal interphalangeal joints: a case-controlled study. Pain Res Treat 2018: 7561209.

10. Hart D, Spector T, Egger P, Coggon D, Cooper C (1994). Defining osteoarthritis of the hand for epidemiological studies: the Chingford Study. Ann Rheum Dis 53: 220-223.

11. Watanabe S, Bruera E (1991) Corticosteroids as adjuvant analgesics. J Pain Symptom Manage 9(70: 442-445.

\section{Your next submission with Juniper Publishers} will reach you the below assets

- Quality Editorial service

- Swift Peer Review

- Reprints availability

- E-prints Service

- Manuscript Podcast for convenient understanding

- Global attainment for your research

- Manuscript accessibility in different formats

( Pdf, E-pub, Full Text, Audio)

- Unceasing customer service

Track the below URL for one-step submission https://juniperpublishers.com/online-submission.php 